Aus der I. Medizinischen Klinik der Universität in Budapest. (Direktor: Hofrat Karl v. Kétly.)

\title{
Ein neues Verfahren zum Nachweis der Azetessigsäure im Urin.
}

Von Béla v. Ondrejovich.

Das Coma diabeticum, als ein bekannter Folgezustand der Säurevergiftung, wies die Forscher schon lange auf die Feststellung derjenigen organischen Säuren hin, welche in grösserer Quantität den obengenannten Zustand hervorrufen.

Die eine dieser Säuren, die Azetessigsäure, haben wir bisher gewöhnlich mit der Gerhardtschen Probe im Urin nachgewiesen. Ein großer Nachteil dieser Probe aber ist, daß sie bei Anwesenheit von Antipyrin, Salizylpräparaten und anderen Stoffen ebenfalls ein positives Resultat gibt; ja selbst nach dem Aufkochen können wir nicht mit Bestimmtheit sagen, ob sich nicht Salizylsäure und Azetessigsäure zusammen im Urin vorfinden. Uebrigens hindern bei der Gerhardt schen Probe auch die ausfallenden Eisenphosphate sehr die Untersuchung.

1899 teilte Arnold $^{2}$ ) eine Azetessigsäurereaktion mit, welche später von Lipliawsky ${ }^{3}$ ) modifiziert wurde; sie konnte aber wegen ihrer

1) Münchener medizinische Wochenschrift 1903, No. 26

2) Wiener klinische Wochenschrift 1899, No. 20.

3) Diese Wochenschrift 1901; No. 10. 
Langwierigkeit und schweren Durchführbarkeit nicht allgemeine Verbreitung finden.

Eine Jodazetessigsäurereaktion machtc schon Mörnerl) bekannt, diese entspricht aber ebenso wic die Schwarz-Bondische ${ }^{2}$ ) Modifikation nicht den praktischen Bedürfnissen, da der ein positives Resultat andeutende Jodazetongeruch einerseits sehr leicht mit dem Geruch der verfliegenden Joddämpfe verwechselt werden kann, anderseits meines Erachtens eine auf dem Geruch basierende Reaktion weder genügend empfindlich noch zuverlässig sein kamn.

Mehr entsprechend als die erwähnetn Reaktionen wäre Linde. mannss ${ }^{3}$ ) Azetessigsäurereaktion, bei welcher aber cbenfalls viele Schwierigkeiten auftauchen.

Diese Reaktion wird folgendernnaßen durchgeführt: Man nimmt $10 \mathrm{ccm}$ des zu untersuchenden Urins, zu welchen man, nach Ansäuerung mit einigen Tropfen Essigsäure, fünf Tropfen Lugolsche Lösung gibt, danach schüttelt mall es mit $2 \mathrm{ccm}$ Chloroform. Ist Azetessigsäure vorhanden, dann bleibt das Chloroform farblos, im entgegengesetzten Falle nimmt es eine Rosafarbe an, indem es das freie Jod löst. Ein Nachteil dieser Reaktion ist meines Erachtens, daß sie zum Nachweis von wenig Azetessigsäure nicht geeignet ist, weil 1 . das Chloroform bei dem Umschütteln mit dem Urin gelb wird, wenn auch freies Jod nicht vorhanden ist (besonders wenn der Urin Galle enthält) und der Uebergang der gelben Farbe in Rosarot keine scharfe Grenze zwischen dem positiven und negativen Resultat gibt; 2. wenn nur wenig Azetessigsäure vorhanden, die zum Urin gegebenen fünf Tropfen Jod manchmal sclıon nach einer Minute gänzlich gebunden werden und das schon früher hinzugegebene Chloroform seine Rosafarbe behält, trotzdem wir ein positives Resultat bekommen müssen, und 3. die gebundene Jodquantität zur quantitativen Bestimmung nicht gebraucht werden kann, da wir nach dem Hinzugeben des Chloroforms mehr Jod nicht zusetzen können, ohne daß das letztere mit dem zur Oberfläche gestiegenen Chloroform in direkte Berührung kommt und darin gelöst wird.

Die von mir ausgearbeitete Reaktion, bei welcher die erwälinten Nachteile ausgeschlossen sind, wird folgendermaßen ausgeführt :

Ich nehme $5 \mathrm{ccm}$ Urin, welchen ich mit fünf Tropfen $50 \%$ iger Essigsäure ansäure. Dazu gebe ich eine $2 \%{ }_{0}$-ige Methylenblaulösung, bis das Ganze eine ausgesprochen blaue Farbe annimmt, wozu gewöhnlich ein Tropfen genügt. Dann gebe ich vier Tropfen Jodtinktur dazu, worauf die ganze Mischung rot wird. Ist aber Azetessigsäure vorhanden, dann wird sie spätestens in einer Minute wieder blau resp. grün; andernfalls behält sie ihre rote Färbung.

Diese Reaktion ist zur quantitativen Abschätzung sehr geeignet.

So können wir auf viel Azetessigsäure schließen, wenn nach Hinzugeben des Jods die rote Färbung garnicht oder nur kurze Zeit sichtbar bleibt; in diesem Falle können wir weiter tropfenweise Jodtinktur hinzugeben, bis die Mischung binnen einer Minute wieder blau resp. zuletzt grün wird. Die Zahl der verbrauchten Jodtropfen steht im Verhältnis zu der Menge der vorhandenen Azetessigsäure.

Hingegen können wir auf wenig Azetessigsäure schließen, wenn die rote Farbe der Mischung nach Hinzugeben der ersten vier Tropfen nahezu eine Minute bestehen bleibt und nach dieser Zeit nicht blau, sondern nur grün wird.

Der bei der Reaktion ablaufende chemische Prozeß basiert darauf, daß die Azetessigsäure in saurer Lösung das Jod zu binden fähig ist. Die Azetessigsäure (anders $\beta$-Oxybuttersäure) wird in saurer Lösung nach Hinzugeben von Jod zu der farblosen und ganz geruchlosen Verbindung Monojodazetessigsäure.

$\mathrm{CH}_{3}-\mathrm{CO}-\mathrm{CH}_{3}-\mathrm{COOH}+\mathrm{J}_{2}=\mathrm{CH}_{3}-\mathrm{CO}-\mathrm{CHJ}-\mathrm{COOH}+\mathrm{HJ}$,

Diese zerfällt aber leicht in Kohlensäure und Jodazeton.

Ist daher im Urin Azetessigsäure vorhanden, so bindet diese nach Ansäuerung das hinzugegebene Jod und enthält bis zur Sättigung kein freies Jod. Ein Urin aber, welcher keine Azetessigsäure enthält, wird schon von vier Tropfen Jod übersättigt, daher Jod auch in ungebundenem Zustand vorhanden ist.

Zum Nachweis des freien Jods, nachdem die Stärke und das Chloroform sich nicht für zweckmäßig erwiesen, fing ich an als Indikator eine wäßrige Lösung von Methylenblau zu gebrauchen, was meinen Zwecken viel mehr entsprach. Die Methylenblaulösung nimmt nämlich schon beim Vorhandensein von Spuren sofort eine rote Farbe an, und, solange sich freies Jod vorfindet, ändert sich auch ihre Farbe nicht. Sobald aber das Jod durch einen Stoff von größerer chemischer Affinität entzogen wird (in unserem Falle durch die Azetessigsäure), gibt das leicht gebundene Jod-Methylenblau gleich ${ }^{-r}$ sein 'Jod $^{-1}$

$\left.{ }^{1}\right)$ Skandinavisches Archiv 1895. _ 2) Wiener klinische Wochenschrift $a b$, und, indem es wieder blau wird, deutet es damit an, daß das ganze Jod verbraucht wurde.

Die starke Ansäuerung des Urins mit viel Essigsäure ist nicht angezeigt, ja sogar nachteilig für die Reaktion, da sie die Fähigkeit des Urins, Jod zu absorbieren, ebenso die Empfindlichkeit der Methylenblaulösung im großen Maße dadurch vermindert, daß in der stark sauer reagierenden Lösung die Jod-Methylenblau-Verbindung eine bleibende grüne Farbe erhält.

Die Absorptionsfähigkeit des Urins für Jod erstreckt sich auf Grund meiner mit zahlreichen Urinen gemachten Experimente auf höchstens drei Tropfen. Diese Jod bindenden Stoffe (wie z. B. das Indikan) sind aber weitaus nicht imstande, so schnell zu wirken, noch eine so große Quantität aufzunelımen wie die Azetessigsäure; daraus ist zu erklären, daß selbst eine große quantitative Veränderung der Bestandteile im Urin nicht so die jod bindende Fähigkeit beeinflußt wie nurSpuren von Azetessigsäure. Dies wird auch dadurch bewiesen, daß die Reaktion bisher in jedem Falle wenigstens doppelt so empfindlich war als die Gerhard tsche Probe.

$\mathrm{Da} B$ bei Vorhandensein einer geringen Menge von Azetessigsäure auch die Schnelligkeit der Jodbindung des Urins geringer ist, ist $\mathrm{zu}$ erklären, wenn wir beobachteten, da $B$ auch die chemische Affinität der Azetessigsäure gegen Jod und so auch die Reaktionsschnelligkeit viel größer ist als die der übrigen im Urin befindlichen Stoffe.

Enthalten also $5 \mathrm{ccm}$ des Urins soviel Azetessigsäure, daß diese auch allein vier Tropfen Jod zu binden imstande ist, dann geschieht diese Absorption sozusagen momentan, das Methylenblau behält seine Farbe. Haben wir es aber mit einem Urin von weniger Azetessigsäuregehalt zu tun, in welchen die Azetessigsäure zur Absorption von vier Tropfen Jod nicht ausreicht, so wird das übrigbleibende Jod gezwungen, sich mit den übrigen Stoffen von minderer Reaktionsschnelligkeit zu verbinden, und so wird die Absorption naturgemäß langsamer ablaufen.

Daher wird das geübte Auge schon aus der Absorptionsschnelligkeit des ersten Jodtropfens ersehen, ob der Urin Azetessigsäure enthält. Ist Azetessigsäure nicht vorhanden, so wird die Absorption gleich des ersten Tropfen Jods durch andere sich im Urin findende Stoffe geschehen; die Absorption läuft naturgemäß langsamer $a b$, was dadurch angedeutet wird, daß das Methylenblau, das eine rote Farbe angenommen, sukzessive zuerst gelb, später grün wird und diese Farbe manchmal stundenlang behält. Dieses Grünwerden soll aber nicht verwechselt werden mit der trübgrünen Färbung nach Hinzugeben von viel Jod, welche bei Vorhandensein vieler Azetessigsäure durch das entstandene Jodazeton und durch die aus dem hinzugegebenen Jod entstandene Jodwasserstoffsäure (Hyperazidität) entstanden ist.

Vorteile der Reaktion sind: 1. Sie ist schnell, nicht kompliziert, zuverlässig. 2. Salizylpräparate, Antipyrin geben sie nicht. 3. Sie gibt ein negatives Resultat, wenn nicht Azetessigsäure, sondern andere Bestandtteile, wie Traubenzucker,

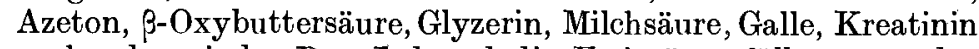
vorhanden sind. Das Jod und die Essigsäure fällen zwar das Eiweiß, dieser Umstand hindert aber die Reaktion nicht. 4. Die Phosphate werden nicht gefällt. 5. Die Reaktion ist empfindlicher als alle bisher bekannten Azetessigsäurereaktionen. 6. Sie ist zur quantitativen Abschätzung sehr geeignet.

Ich will noch erwähnen, daß die Reaktion, ebenso wie die übrigen, nach dem Aufkochen und, wenn Formalin in größerer Menge längere Zeit einwirkt, infolge des Zerfalls der Azetessigsäure ausbleibt. 